\section{Age Factor Influencing on Patients Subjected to Coronary Artery Bypass Grafting}

\author{
Adilova IG ${ }^{1}$, Salomova $\mathrm{AF}^{1}$ and Abdurakhmanov $\mathrm{ZM}^{2 *}$ \\ ${ }^{1}$ Deprtment of Cardiology, Tashkent Institute of Postgraduate Medical \\ Education, Tashkent, Uzbekistan
}

${ }^{2}$ Department of General Surgery, Bukhara State Medical Institute, Bukhara, Uzbekistan

\begin{abstract}
Objective: To study age-dependent trends in long-term survival with its predictors in patients who underwent isolated CABG.

Methods: 177 consecutive patients, operated on within 2014 were included in our study. The patients were divided into two age groups for the purposes of the statistical analysis: $<60$ year's $(n=96)$, and $\geq 60$ years $(n=81)$. The mean age was $54.5 \pm 2.9$ year's in the group of $<60$ years, whereas $63.6 \pm 2.5$ in the $\geq 60$ years. In both groups, the impact of the prevalence of comorbidities, severity of coronary lesion, revascularization degree (complete/incomplete) on postoperative outcome was assessed. Furthermore, the whole predictors of mortality were identified according to both age groups by means of multivariate analysis. End point of this study was overall survival. All data were obtained from patients' medical, out-patient follow-up records, operative reports.
\end{abstract}

Results: The mean follow-up of the overall cohort was $5.1 \pm 1.7$ years. Chronic pulmonary disease, extracardiac arteriopathy, and neurologic dysfunction disease were significantly less frequent in the group of $<60$ years, whereas the prevalence of BMI $\geq 30$, unstable angina, previous myocardial infarction, and preoperative severe depressed left ventricular ejection fraction were significantly higher in this population. At 5 years follow-up, survival rate was $94.8 \%$ in patients under 60 years (5 patients), $90.1 \%$ (8 patients) in those aged 60 and more year's $(p<0.001)$. By multivariate analysis, previous myocardial infarction, chronic renal failure, diabetes, chronic

*Corresponding author: Abdurakhmanov ZM, Department of General Surgery, Bukhara State Medical Institute, Bukhara, Uzbekistan, Tel: +998 907180051 ; E-mail: z_abdurakhmanov@yahoo.com

Citation: Adilova IG, Salomova AF, Abdurakhmanov ZM (2020) Age Factor Influencing on Patients Subjected to Coronary Artery Bypass Grafting. J Angiol Vasc Surg 5: 038.

Received: February 14, 2020; Accepted: March 05, 2020; Published: March 12,2020

Copyright: ( 2020 Adilova IG, et al. This is an open-access article distributed under the terms of the Creative Commons Attribution License, which permits unrestricted use, distribution, and reproduction in any medium, provided the original author and source are credited. pulmonary disease, extracardiac arteriopathy and left main coronary artery disease were considered as independent predictors of mortality. The area under the receiver operating characteristic curve was 0.834 ( $p<0.001,95 \% \mathrm{Cl}$ : 0.724-0.902).

Conclusion: Despite the coronary artery bypass grafting are more secure for both groups, a strict attention should be focused in order to design and improve preventive strategies aiming to reduce the impact of specific cardiovascular risk factors on younger patients, such as diet, lifestyle, weight control and more aggressive medical therapy. The reasonable revascularization strategy with its underscored threshold for elderly patients with multivessel and left main coronary artery diseases, potential risk factors for death as concomitant pathologies should be elaborated.

Keywords: Coronary artery bypass grafting; Coronary artery disease; Multivessel disease

\section{Introduction}

Considering the increase in life expectancy of the world population in general in recent decades and the prevalence of cardiovascular diseases among the elderly, the percentage of this population who needs cardiovascular surgery is increasing, including those who have reached or exceeded the average life expectancy for Uzbekistanians (72 years of age) [1]. Meanwhile, major surgeries in elderly populations, such as cardiac surgeries (especially those 65 years of age or older), are associated with high morbidity and mortality, while aging simultaneously results in the reduction of functional reserves of various organs and systems [2]. The prevalence of other comorbidities among the elderly is high [3].

With regard to young patients, premature Coronary Artery Disease (CAD) is a rapidly progressive form of the disease [4]. Numerous studies reported that young patients with CAD have a significant prevalence of classic cardiovascular risk factors $[5,6]$, and that the premature clinical onset of their symptoms can be more aggressive than in elderly patients [7]. In fact, young adults who undergo coronary artery revascularization are a specific subpopulation of patients, and there have been few studies on survival data, cardiovascular events [8]. Young patients undergoing Coronary Artery Bypass Grafting $(\mathrm{CABG})$ demonstrate survival rates similar to those of Percutaneous Coronary Intervention (PCI), but lower rates of repeated revascularization [9]. There are few long-term reports of the impact of age stratification on CABG outcomes both for young and elderly patients.

The aim of our study was to investigate age-dependent trends in long-term survival with its predictors in patients who underwent isolated $\mathrm{CABG}$.

\section{Methods}

Within 2014, data of all patients undergoing coronary CABG in Republican Specialized Center of Surgery (Tashkent, Uzbekistan) were gathered. All data were obtained from patients medical, out-patient follow-up records, operative reports. The requirement for 
Citation: Adilova IG, Salomova AF, Abdurakhmanov ZM (2020) Age Factor Influencing on Patients Subjected to Coronary Artery Bypass Grafting. J Angiol Vasc Surg 5: 038 .

individual patient consent was waived because of the retrospective design of the study and because data were collected from routine care procedures. All data were anonymized and deidentified prior to statistical analysis.

Exclusion study criteria were emergency, cardiogenic shock, associated valve surgery procedures, major aortic surgery, and supra-aortic vessels disease requiring surgery. After these exclusions, we filtered 177 patients subjected to isolated CABG. The patients were divided into two age bands for the purposes of the statistical analysis: $<60$ years $(n=96)$, and $\geq 60$ years $(n=81)$.

Decisions about the type of treatment were taken according to local practices and there were no standard regional protocols. The choice of CABG technique, performed either with the use of extracorporeal circulation or off-pump, was left to the surgeon's discretion. Whenever possible, the left internal thoracic artery was used preferentially for revascularization of the Left Anterior Descending artery (LAD). Complete revascularization was performed with other arterial conduits, namely, radial artery or and saphenous vein grafts. Follow-up angiography was not performed routinely in either group of patients. All-cause death included overall mortality occurring during the index hospital admission or thereafter. Cardiac death was defined as any death due to a cardiac cause (e.g., Myocardial Infarction (MI), low output failure, and fatal arrhythmia), and other types were procedure-related death and death of unknown cause.

\section{Statistical Analysis}

Demographic and clinical features of the patients were presented as counts, percentages, and were compared between the two age classes, using the Chi-square test. Independent predictors of 5 years mortality risk were estimated using a stepwise multivariable Cox proportional hazards model. All the analyses were performed with SPSS version 22.0.

\section{Results}

The entire study cohort showed that patient risk profiles differed significantly between the groups (Table 1 ). The prevalence of patients under 60 is $54.2 \%$ (96 of 177 patients). Patients over 60 show a significantly higher prevalence of baseline comorbidities. In particular, serum creatinine, diabetes, chronic pulmonary disease, systemic arterial hypertension, extracardiac arteriopathy, and neurologic dysfunction disease were significantly less frequent in this younger population (Table 1).

On the other hand, the prevalence of Body Mass Index (BMI) $\geq 30$ $\mathrm{Kg} / \mathrm{m} 2$, unstable angina, Previous Myocardial Infarction (PMI) was higher in the group of $<60$ year's than in patients aged 60 and more year's. Moreover, patients $<60$ reported more frequently a preoperative severe depressed Left Ventricular Ejection Fraction (LVEF), although this was not statistically significant $(\mathrm{p}=0.147)$. We found that coronary revascularization was performed off-pump more frequently in patients over 60 , whereas patients under 60 received more frequently on pump total arterial revascularization $(\mathrm{p}<0.001)$ (Table 1).

Analysis of the coronaroangiography results showed that the most pronounced changes in the coronary bed were detected in patients over 60 years. Multivessel disease in patients of the latter group significantly prevailed over that of $<60$ years group. (96.3\%, 89.6\% respectively). Moreover, left main coronary artery disease was observed significantly 3,7 times more in patients over 60 (Figure 1).

\begin{tabular}{|c|c|c|c|c|}
\hline \multicolumn{2}{|c|}{ Patients characteristics } & $\begin{array}{c}<60 \mathrm{yrs} \\
(\mathrm{n}=96) \%\end{array}$ & $\begin{array}{c}\geq 60 \mathrm{yrs} \\
(\mathrm{n}=81) \%\end{array}$ & $\mathbf{p}$ \\
\hline \multicolumn{2}{|r|}{ Age } & $54.5 \pm 2.9$ & $63.6 \pm 2.5$ & $<0.001$ \\
\hline \multicolumn{2}{|c|}{ Male, n (\%) } & $82(85.4)$ & $71(90.1)$ & $<0.0001$ \\
\hline \multicolumn{2}{|c|}{$\mathrm{BMI} \geq 30 \mathrm{~kg} / \mathrm{m} 2, \mathrm{n}(\%)$} & $24(25)$ & $17(20.9)$ & $<0.0001$ \\
\hline \multicolumn{2}{|c|}{ Urgency, n (\%) } & 1(1) & - & $=0.038$ \\
\hline \multicolumn{2}{|c|}{ Unstableangina, n (\%) } & $15(15.6)$ & $12(14.8)$ & $<0.0002$ \\
\hline \multicolumn{2}{|c|}{ III/IV CCS class, $\mathrm{n}(\%)$} & $74(77)$ & $67(82.7)$ & $<0.0001$ \\
\hline \multicolumn{2}{|c|}{ LVEF (\%) } & $51.3 \pm 6.5$ & $51.1 \pm 6.5$ & $=0.147$ \\
\hline \multirow{3}{*}{$\begin{array}{l}\text { LV Dysfunc- } \\
\text { tion, n (\%) }\end{array}$} & Severe (EF 30-44\%) & $19(19.8)$ & $14(17.3)$ & $=0.45$ \\
\hline & Moderate (EF 45-54\%) & $41(42.7)$ & $35(45.6)$ & \\
\hline & Mild (EF $\geq 55 \%)$ & $36(37.5)$ & $28(37.0)$ & \\
\hline \multicolumn{2}{|c|}{ III/IV NYHA class, n (\%) } & $10(10.4)$ & $9(11.1)$ & $<0.001$ \\
\hline \multicolumn{2}{|c|}{ Previousmyocardialinfarction, n (\%) } & $44(45.8)$ & $35(43.2)$ & $<0.0001$ \\
\hline \multicolumn{2}{|c|}{ Serum creatinine $\geq 177 \mathrm{mmol} / \mathrm{l}, \mathrm{n}(\%)$} & $3(3.1)$ & $5(6.1)$ & $=0.037$ \\
\hline \multicolumn{2}{|c|}{ Diabetes, n (\%) } & $18(18.7)$ & $16(21)$ & $<0.0001$ \\
\hline \multicolumn{2}{|c|}{$\mathrm{SAH}, \mathrm{n}(\%)$} & $64(66.7)$ & $66(81.5)$ & $=0.824$ \\
\hline \multicolumn{2}{|c|}{ Chronicpulmonarydisease, $\mathrm{n}(\%)$} & $1(1)$ & $2(2.5)$ & $<0.0001$ \\
\hline \multicolumn{2}{|c|}{ Extracardiacarteriopathy, n (\%) } & $3(3.1)$ & $5(6.2)$ & $<0.0001$ \\
\hline \multicolumn{2}{|c|}{ Neurologicaldysfunctiondisease, n (\%) } & - & $2(2,5)$ & $=0,048$ \\
\hline \multicolumn{2}{|c|}{ Off-pump } & $4(4.2 \%)$ & $10(12.3 \%)$ & $<0.001$ \\
\hline \multicolumn{2}{|c|}{ Previous PCI } & $1(1)$ & - & $<0.001$ \\
\hline \multicolumn{2}{|c|}{ CPB time (min) } & $93.98 \pm 23.72$ & $88.81 \pm 16.67$ & $=0.035$ \\
\hline
\end{tabular}

Table 1: Baseline characteristics and preoperative clinical data of patients according to different age classes.

BMI: Body Mass Index; CCS: Canadian Cardiovascular Society grading of angina pectoris; LVEF: Left Ventricular Ejection Fraction; NYHA: New York Heath Association; SAH: Systemic Arterial Hypertension; PCI: Percutaneous Coronary Intervention; LMCA: Left Main Coronary Artery; CPB: Cardiopulmonary Bypass

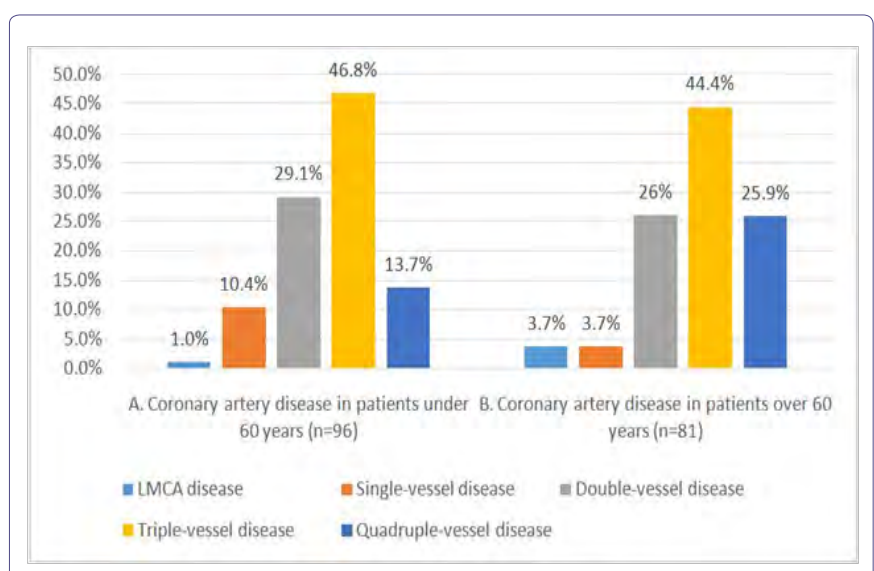

Figure 1: Coronaroangiography data $(\mathrm{n}=177)$.

According to the study data, patients of the both groups mostly experienced a triple-vessel disease. The latter disease was identified more often in both groups with concomitant diabetes $(43.7 \%$ and $44.4 \%$ respectively). On top of that, a quadruple-vessel disease occurred in $25 \%$ patients of $\geq 60$ years who had diabetes. 
Citation: Adilova IG, Salomova AF, Abdurakhmanov ZM (2020) Age Factor Influencing on Patients Subjected to Coronary Artery Bypass Grafting. J Angiol Vasc Surg 5: 038 .

As shown in table 2, LAD was mostly exposed to atherosclerotic stenosis in both groups. Circumflex artery lesions were more often found in patients $\geq 60$ years old in comparison to $\geq 60$ years old, $17 \%$ and $12 \%$, respectively, while right coronary artery lesions were more common in patients $<60$ years old compared to $\geq 60$ years old, $11 \%$ and $8 \%$, respectively.

\begin{tabular}{|c|c|c|c|}
\hline \multirow{2}{*}{ Coronary artery disease } & $\mathbf{6 6 0}$ yrs & $\mathbf{2 6 0}$ yrs & \multirow{2}{*}{$\mathbf{p}$} \\
\cline { 2 - 3 } & $\begin{array}{c}\text { Total lesions } \\
\mathbf{( n = 2 5 0 )}\end{array}$ & $\begin{array}{c}\text { Total lesions } \\
\mathbf{( n = 2 3 2 )}\end{array}$ & \\
\hline LAD, n (\%) & $95(31 \%)$ & $80(34.5 \%)$ & $<0.001$ \\
\hline DA, n (\%) & $14(4 \%)$ & $18(7.7 \%)$ & $<0.001$ \\
\hline Cx, n (\%) & $29(11.6 \%)$ & $40(17.2 \%)$ & $<0.001$ \\
\hline OM-1, n (\%) & $36(14.4 \%)$ & $28(12 \%)$ & $<0.001$ \\
\hline OM-2, n (\%) & $2(1 \%)$ & $4(1.7 \%)$ & $<0.001$ \\
\hline AI, n (\%) & $11(4.4 \%)$ & $8(3.4 \%)$ & $<0.001$ \\
\hline RCA, n (\%) & $27(10.8 \%)$ & $19(8.1 \%)$ & $<0.001$ \\
\hline PDA, n (\%) & $36(14.4 \%)$ & $35(15 \%)$ & $<0.001$ \\
\hline tion, n (\%) & $87(90.6)$ & $68(83.4)$ & $<0.0001$ \\
\hline \multicolumn{2}{|c|}{ Table 2: Types and quantity of coronary artery disease. } \\
\hline
\end{tabular}

LAD: Left Anterior Descending Artery; DA: Diagonal Artery; Cx: Circumflex artery; OM-1: Obtuse Marginal-1 artery; OM-2: Obtuse Marginal-2 artery; AI: Intermedia Artery; RCA: Right Coronary Artery; PDA: Posterior Descending Artery

Table 3 reports multivariate analysis with significant independent predictors of mortality at 5 years. The area under the receiver operating characteristic curve was $0,834(\mathrm{P}<0.001,95 \%$ CI: 0.715-0.914).

\begin{tabular}{|c|c|c|c|c|}
\hline \multicolumn{2}{|c|}{ Parameter } & HR & $\begin{array}{c}\mathbf{9 5 \%} \text { CI of } \\
\text { HR }\end{array}$ & $\boldsymbol{P}$ \\
\hline$<60$ years old & Previousmyocardialinfarction & 1.7 & $1.1-1.6$ & $=0.0048$ \\
\hline & Serum creatinine $\geq 177 \mathrm{mmol} / 1$ & 2.5 & $1.5-3.2$ & $<0.0002$ \\
\cline { 2 - 5 } & Diabetes & 1.8 & $1.3-1.8$ & $<0.0002$ \\
\cline { 2 - 5 }$\geq 60$ years old & Chronic pulmonary disease & 2.1 & $1.3-2.5$ & $<0.0005$ \\
\cline { 2 - 5 } & Extracardiac arteriopathy & 1.9 & $1.4-2.1$ & $<0.0001$ \\
\cline { 2 - 5 } & LMCA disease & 2.7 & $1.2-4.4$ & $=0.023$ \\
\hline
\end{tabular}

Table 3: Predictors for 5-year's mortality risk (Cox proportional hazards model).

CI: Confidence Interval; HR: Hazard Ration; LMCA: Left Main Coronary Artery

As given in figure 2, despite the indication to operation, few patients of $<60(6.3 \%)$ and $\geq 60(16 \%)$ did not undergo CABG due to multiple risk factors and severity of atherosclerotic disease, consequently $\geq 60$ aged patients $9.7 \%$ less operated in comparison to the patients group of $<60(p<0.05)$. Besides complete revascularization was carried out in the group of $\geq 60$ aged on $7.2 \%$ less than in that of $<60(\mathrm{p}<0.05)$.

The mean follow-up of the overall cohort was $5.1 \pm 1.7$ years. At follow-up, survival rate was $94.8 \%$ in patients under 60 years ( 5 patients), $90.1 \%$ (8 patients) in those aged 60 and more years.

\section{Discussion}

Recent studies conducted in Western Countries have found that the incidence of CAD has declined in the general population over the last few decades $[10,11]$, probably due to better prevention of cardiovascular risk. On the other hand, the incidence of CAD, including acute coronary artery syndromes, among young to middle-aged adults has been shown to have increased [12]. Previous studies of CAD in young adults have mostly been single-center analyses $[7,8]$, and few have been designed with the aim of studying young patients undergoing coronary revascularization [6,8,9,13-15].

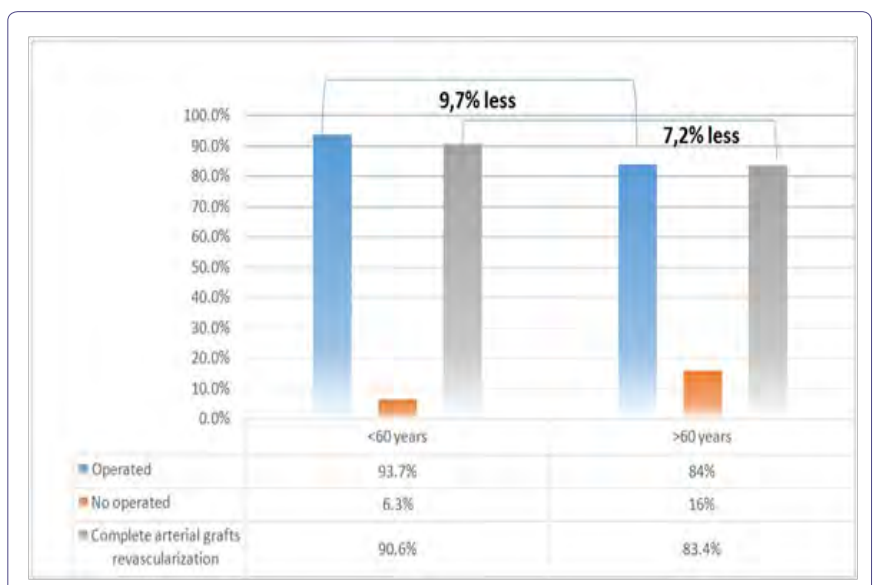

Figure 2: Percentage of operated/no operated patients, complete revascularization of both groups $(\mathrm{n}=177)$.

The aim of our retrospective study was to investigate age-dependent trends in mortality in a population of patients undergoing isolated CABG. The main findings of this study are as follows. Of particular interest is that at 5 years the $<60$ group who underwent CABG reported unadjusted significantly lower long-term mortality than older patients $(5.2 \%$ versus $9.9 \%)$.

It is well known that cardiovascular risk factors vary with regard to their impact on age of presentation with CAD. Our study confirms that patients younger than 60 have a different clinical pattern of presentation of CAD in comparison with elderly patients. Particularly, obesity, the history of previous myocardial infarction, the presence of depressed LVEF, and a history of previous PCI have been found to be highly prevalent among patients $<60$, confirming the results of a recent study by Moussa et al., [16]. Obesity has already been recognized as an independent risk factor for CAD [17] and recently a close association between severity of obesity, measured by BMI $>30 \mathrm{~kg} / \mathrm{m} 2$, and a progressive reduction in the mean age of patients with symptomatic CAD has been demonstrated [18]. In particular, abdominal obesity has been found to be closely associated with the risk of myocardial infarction [19] and this is observed more often in men $[20,21]$. On the basis of these observations and our results, it is reasonable to postulate that the risk of CAD due to obesity may be higher in men than women. On the other hand, systemic comorbidities usually associated with severe CAD, such as chronic pulmonary disease, diabetes, stroke, and extracardiac arteriopathy in our study, proved to be less frequent in patients aged $<60$. This is consistent with the previous international literature $[22,23]$ and may be explained by the fact that the onset of diabetes mellitus and systemic hypertension usually occurs later in life, and their effect on the pathogenesis of CAD may require several years or decades to become clinically evident. Obviously, in terms of our data, the accumulation of these concomitant pathologies explains the higher rate of off-pump bypass grafting in elderly group. The purpose of this study was not to 
Citation: Adilova IG, Salomova AF, Abdurakhmanov ZM (2020) Age Factor Influencing on Patients Subjected to Coronary Artery Bypass Grafting. J Angiol Vasc Surg 5: 038.

primarily investigate the risk factors determining premature $\mathrm{CAD}$, but our findings clearly confirm that the pathogenesis of coronary artery disease remains complex and that both genetic and environmental factors contribute to the early onset of coronary artery disease.

Long-term mortality was considerably lower in patients $<60$ years than in patients $\geq 60$, and this result is consistent with mortality rates reported in previous studies of young patients undergoing CABG $[9,12,16,24]$. In fact, in our study multivariate analysis confirmed that all classic clinical cardiac conditions and systemic comorbidities (history of previous myocardial infarction in the younger group, whereas, chronic renal failure, diabetes, chronic pulmonary disease, extra-cardiac arteriopathy, and left main coronary disease in the elderly group) are independent risk factors for mortality at 5 years.

The significantly lower rate of extracardiac arteriopathy reported in younger patient subgroups may also partly explain the significantly better stroke rates in patients under 60 .

Of particular interest is that multivessel disease in patients of the $\geq 60$ years group significantly prevailed over that of $<60$ years group that coincides with previous study [25]. Basing on our data results, $\geq 60$ aged patients were conducted CABG $9.7 \%$ less in comparison to the patients' group of $<60$. This may be explained by the fact that the incidence of significant arterial calcification increases with age, raising the complexity of operation [26]. Due to severe diffuse coronary lesion, incomplete revascularization was higher in $\geq 60$ years group that may consistent with a lower survival rate as demonstrated in the latest study [27].

\section{Conclusion}

To conclude, CABG is safe and effective for both groups. Nevertheless, to increase the durability (considering not only the survival rates, but also the influence of the outcomes of surgery on quality of life) of myocardial revascularization, a strict attention should be focused in order to design and improve preventive strategies aiming to reduce the impact of specific cardiovascular risk factors on younger patients, such as diet, lifestyle, weight control, and more aggressive medical therapy. On top of that more often elderly patients are not capable of being operated due their complicated coronary anatomy that induces us to work out the strategy and borderline of the need for surgery. The reasonable revascularization strategy, with its underscored threshold for elderly patients with multivessel and left main coronary artery diseases, concomitant pathologies determined as potential risk factors for death, should be also elaborated.

\section{References}

1. Knoema (2017) The state committee of the Republic of Uzbekistan on statistics. Knoema, Tashkent, Uzbekistan.

2. Lakatta EG, Levy D (2003) Arterial and cardiac aging: major shareholders in cardiovascular disease enterprises: Part II: the aging heart in health: links to heart disease. Circulation 107: 346-354.

3. Oskvig RM (1999) Special problems in the elderly. Chest 115: 158-164.

4. Klein LW, Nathan S (2003) Coronary artery disease in young adults. Journal of the American College of Cardiology 41: 529-531.

5. Zimmerman FH, Cameron A, Fisher LD, Ng G (1995) Myocardial infarction in young adults: Angiographic characterization, risk factors and prognosis (coronary artery surgery study registry). J Am Coll Cardiol 26: 654-661.
6. Mukherjee D, Hsu A, Moliterno DJ, Lincoff AM, Goormastic M, et al. (2003) Risk factors for premature coronary artery disease and determinants of adverse outcomes after revascularization in patients $<$ or $=40$ years old. Am J Cardiol 92: 1465-1467.

7. Cole JH, Miller JI 3rd, Sperling LS, Weintraub WS (2003) Long-term follow-up of coronary artery disease presenting in young adults. J Am Coll Cardiol 41: 521-528.

8. Khawaja FJ, Rihal CS, Lennon RJ, Holmes DR, Prasad A (2011) Temporal trends (over 30 years), clinical characteristics, outcomes, and gender in patients $\leq 50$ years of age having percutaneous coronary intervention. Am J Cardiol 107: 668-674.

9. Biancari F, Gudbjartsson T, Heikkinen J, Anttila V, Mäkikallio T, et al. (2014) Comparison of 30-day and 5-year outcomes of percutaneous coronary intervention versus coronary artery bypass grafting in patients aged $\leq 50$ years (the Coronary aRtery diseAse in younG adultS Study). Am J Cardiol 114: 198-205.

10. Ford ES, Capewell S (2007) Coronary heart disease mortality among young adults in the U.S. from 1980 through 2002: concealed leveling of mortality rates. J Am Coll Cardiol 50: 2128-2132.

11. Nedkoff LJ, Briffa TG, Preen DB, Sanfilippo FM, Hung J, et al. (2011) Age- and sex-specific trends in the incidence of hospitalized acute coronary syndromes in Western Australia. Circ Cardiovasc Qual Outcomes 4: 557-564.

12. Agarwal S, Sud K, Thakkar B, Menon V, Jaber WA, et al. (2017) Changing Trends of Atherosclerotic Risk Factors Among Patients with Acute Myocardial Infarction and Acute Ischemic Stroke. Am J Cardiol 119: 15321541.

13. Flather M, Rhee JW, Boothroyd DB, Boersma E, Brooks MM, et al. (2012) The effect of age on outcomes of coronary artery bypass surgery compared with balloon angioplasty or bare-metal stent implantation among patients with multivessel coronary disease. A collaborative analysis of individual patient data from 10 randomized trials. J Am Coll Cardiol 60: 2150-2157.

14. Lichtman JH, Wang Y, Jones SB, Leifheit-Limson EC, Shaw LJ, et al. (2014) Age and sex differences in inhospital complication rates and mortality after percutaneous coronary intervention procedures: evidence from the NCDR(®).Am Heart J 167: 376-383.

15. Kaneko H, Yajima J, Oikawa Y, Tanaka S, Fukamachi D, et al. (2014) Impact of aging on the clinical outcomes of Japanese patients with coronary artery disease after percutaneous coronary intervention. Heart Vessels 29: 156-164.

16. Moussa ID, Klein LW, Shah B, Mehran R, Mack MJ, et al. (2013) Consideration of a new definition of clinically relevant myocardial infarction after coronary revascularization: an expert consensus document from the Society for Cardiovascular Angiography and Interventions (SCAI). J Am Coll Cardiol 62: 1563-1570.

17. Lu Y, Hajifathalian K, Ezzati M, Woodward M, Rimm EB, et al. (2014) Metabolic mediators of the effects of body-mass index, overweight, and obesity on coronary heart disease and stroke: a pooled analysis of 97 prospective cohorts with 1.8 million participants. Lancet 383: 970-983.

18. Atique SM, Shadbolt B, Marley P, Farshid A (2016) Association between Body Mass Index and Age of Presentation with Symptomatic Coronary Artery Disease. Clin Cardiol 39: 653-657.

19. Yusuf S, Hawken S, Ounpuu S, Dans T, Avezum A, et al. (2004) Effect of potentially modifiable risk factors associated with myocardial infarction in 52 countries (the INTERHEART study): case-control study. Lancet 364 : 937-952.

20. See R, Abdullah SM, McGuire DK, Khera A, Patel MJ, et al. (2007) The association of differing measures of overweight and obesity with prevalent atherosclerosis: the Dallas Heart Study. J Am Coll Cardiol 50: 752-759. 
Citation: Adilova IG, Salomova AF, Abdurakhmanov ZM (2020) Age Factor Influencing on Patients Subjected to Coronary Artery Bypass Grafting. J Angiol Vasc Surg 5: 038 .

\section{- Page 5 of 6 -}

21. Matsis K, Holley A, Al-Sinan A, Matsis P, Larsen PD et al. (2017) Differing Clinical Characteristics between Young and Older Patients Presenting with Myocardial Infarction. Heart Lung Circ 26: 566-571.

22. Choudhury L, Marsh JD (1999) Myocardial infarction in young patients. American Journal of Medicine 107: 254-261.

23. Reibis R, Treszl A, Wegscheider K, Bestehorn K, Karmann B, et al. (2012) Disparity in risk factor pattern in premature versus late-onset coronary artery disease: A survey of 15,381 patients. Vasc Health Risk Manag 8: 473-481.

24. Dalén M, Ivert T, Holzmann MJ, Sartipy U (2015) Coronary artery bypass grafting in patients 50 years or younger: a Swedish nationwide cohort study. Circulation 131: 1748-1754.
25. Posenau JT, Wojdyla DM, Shaw LK, Alexander KP, Ohman EM, et al. (2017) Revascularization Strategies and Outcomes in Elderly Patients with Multivessel Coronary Disease. Ann Thorac Surg 104: 107-115.

26. Newman AB, Naydeck BL, Sutton-Tyrrell K, Feldman A, Edmundowicz D, et al. (2001) Coronary artery calcification in older adults to age 99: prevalence and risk factors. Circulation 104: 2679-2684.

27. Diegeler A, Börgermann J, Kappert U, Hilker M, Doenst T, et al. (2019) Five-Year Outcome After Off-Pump or On-Pump Coronary Artery Bypass Grafting in Elderly Patients. Circulation 139: 1865-1871. 


\section{II \\ Hetario}

Advances In Industrial Biotechnology | ISSN: 2639-5665

Advances In Microbiology Research | ISSN: 2689-694X

Archives Of Surgery And Surgical Education | ISSN: 2689-3126

Archives Of Urology

Archives Of Zoological Studies | ISSN: 2640-7779

Current Trends Medical And Biological Engineering

International Journal Of Case Reports And Therapeutic Studies | ISSN: 2689-310X

Journal Of Addiction \& Addictive Disorders | ISSN: 2578-7276

Journal Of Agronomy \& Agricultural Science | ISSN: 2689-8292

Journal Of AIDS Clinical Research \& STDs | ISSN: 2572-7370

Journal Of Alcoholism Drug Abuse \& Substance Dependence | ISSN: 2572-9594

Journal Of Allergy Disorders \& Therapy | ISSN: 2470-749X

Journal Of Alternative Complementary \& Integrative Medicine | ISSN: 2470-7562

Journal Of Alzheimers \& Neurodegenerative Diseases | ISSN: 2572-9608

Journal Of Anesthesia \& Clinical Care | ISSN: 2378-8879

Journal Of Angiology \& Vascular Surgery | ISSN: 2572-7397

Journal Of Animal Research \& Veterinary Science | ISSN: 2639-3751

Journal Of Aquaculture \& Fisheries | ISSN: 2576-5523

Journal Of Atmospheric \& Earth Sciences | ISSN: 2689-8780

Journal Of Biotech Research \& Biochemistry

Journal Of Brain \& Neuroscience Research

Journal Of Cancer Biology \& Treatment | ISSN: 2470-7546

Journal Of Cardiology Study \& Research | ISSN: 2640-768X

Journal Of Cell Biology \& Cell Metabolism | ISSN: 2381-1943

Journal Of Clinical Dermatology \& Therapy | ISSN: 2378-8771

Journal Of Clinical Immunology \& Immunotherapy | ISSN: 2378-8844

Journal Of Clinical Studies \& Medical Case Reports | ISSN: 2378-8801

Journal Of Community Medicine \& Public Health Care | ISSN: 2381-1978

Journal Of Cytology \& Tissue Biology | ISSN: 2378-9107

Journal Of Dairy Research \& Technology | ISSN: 2688-9315

Journal Of Dentistry Oral Health \& Cosmesis | ISSN: 2473-6783

Journal Of Diabetes \& Metabolic Disorders | ISSN: 2381-201X

Journal Of Emergency Medicine Trauma \& Surgical Care | ISSN: 2378-8798

Journal Of Environmental Science Current Research | ISSN: 2643-5020

Journal Of Food Science \& Nutrition | ISSN: 2470-1076

Journal Of Forensic Legal \& Investigative Sciences | ISSN: 2473-733X

Journal Of Gastroenterology \& Hepatology Research | ISSN: 2574-2566
Journal Of Genetics \& Genomic Sciences | ISSN: 2574-2485

Journal Of Gerontology \& Geriatric Medicine | ISSN: 2381-8662

Journal Of Hematology Blood Transfusion \& Disorders | ISSN: 2572-2999

Journal Of Hospice \& Palliative Medical Care

Journal Of Human Endocrinology | ISSN: 2572-9640

Journal Of Infectious \& Non Infectious Diseases | ISSN: 2381-8654

Journal Of Internal Medicine \& Primary Healthcare | ISSN: 2574-2493

Journal Of Light \& Laser Current Trends

Journal Of Medicine Study \& Research | ISSN: 2639-5657

Journal Of Modern Chemical Sciences

Journal Of Nanotechnology Nanomedicine \& Nanobiotechnology | ISSN: 2381-2044

Journal Of Neonatology \& Clinical Pediatrics | ISSN: 2378-878X

Journal Of Nephrology \& Renal Therapy | ISSN: 2473-7313

Journal Of Non Invasive Vascular Investigation | ISSN: 2572-7400

Journal Of Nuclear Medicine Radiology \& Radiation Therapy | ISSN: 2572-7419

Journal Of Obesity \& Weight Loss | ISSN: 2473-7372

Journal Of Ophthalmology \& Clinical Research | ISSN: 2378-8887

Journal Of Orthopedic Research \& Physiotherapy | ISSN: 2381-2052

Journal Of Otolaryngology Head \& Neck Surgery | ISSN: 2573-010X

Journal Of Pathology Clinical \& Medical Research

Journal Of Pharmacology Pharmaceutics \& Pharmacovigilance | ISSN: 2639-5649

Journal Of Physical Medicine Rehabilitation \& Disabilities | ISSN: 2381-8670

Journal Of Plant Science Current Research | ISSN: 2639-3743

Journal Of Practical \& Professional Nursing | ISSN: 2639-5681

Journal Of Protein Research \& Bioinformatics

Journal Of Psychiatry Depression \& Anxiety | ISSN: 2573-0150

Journal Of Pulmonary Medicine \& Respiratory Research | ISSN: 2573-0177

Journal Of Reproductive Medicine Gynaecology \& Obstetrics | ISSN: 2574-2574

Journal Of Stem Cells Research Development \& Therapy | ISSN: 2381-2060

Journal Of Surgery Current Trends \& Innovations | ISSN: 2578-7284

Journal Of Toxicology Current Research | ISSN: 2639-3735

Journal Of Translational Science And Research

Journal Of Vaccines Research \& Vaccination | ISSN: 2573-0193

Journal Of Virology \& Antivirals

Sports Medicine And Injury Care Journal | ISSN: 2689-8829

Trends In Anatomy \& Physiology | ISSN: 2640-7752

Submit Your Manuscript: https://www.heraldopenaccess.us/submit-manuscript 